\title{
Changes in stigma and help-seeking in relation to postpartum depression: Non-clinical parenting intervention sample
}

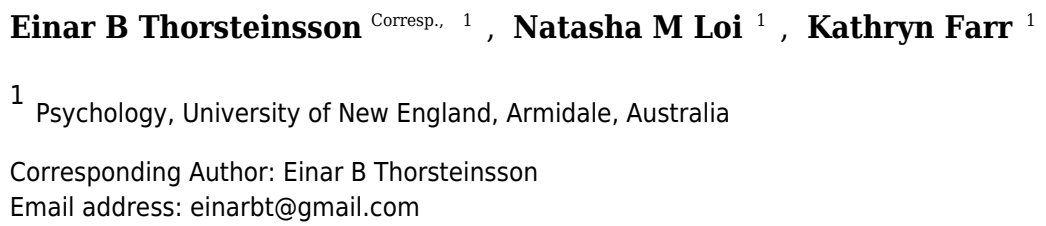

Postpartum depression (PPD) is a prevalent mental illness affecting women, and less commonly, men in the weeks and months after giving birth. Despite the high incidence of PPD in Australia, rates for help-seeking remain low, with stigma and discrimination frequently cited as the most common deterrents to seeking help from a professional source. The present study sought to investigate PPD stigma in a sample of parents and to examine the effects of an intervention on stigma and help-seeking behaviour. A total of 212 parents aged 18 to 71 years ( $M=36.88,194$ females) completed measures of personal and perceived PPD stigma and attitudes towards seeking mental health services and were randomly assigned to one of four groups: an intervention group (video documentary or factsheet related to PPD) or a control group (video documentary or factsheet not related to PPD). Results showed that there were no effects for type of intervention on either personal or perceived PPD stigma scores. No effect was found for help-seeking propensity. Males had higher personal PPD stigma than females and older age was associated with lower personal PPD stigma. Familiarity with PPD was associated with perceived PPD stigma in others but not personal PPD stigma. More work needs to be conducted to develop interventions to reduce PPD stigma in the community. 
Corresponding author:

Associate Professor Einar B. Thorsteinsson

Psychology

University of New England

Armidale, NSW 2351

Australia

email: ethorste@une.edu.au 
Abstract

29 Postpartum depression (PPD) is a prevalent mental illness affecting women, and less commonly,

30 men in the weeks and months after giving birth. Despite the high incidence of PPD in Australia,

31 rates for help-seeking remain low, with stigma and discrimination frequently cited as the most

32 common deterrents to seeking help from a professional source. The present study sought to

33 investigate PPD stigma in a sample of parents and to examine the effects of an intervention on

34 stigma and help-seeking behaviour. A total of 212 parents aged 18 to 71 years $(M=36.88,194$

35 females) completed measures of personal and perceived PPD stigma and attitudes towards

36 seeking mental health services and were randomly assigned to one of four groups: an

37 intervention group (video documentary or factsheet related to PPD) or a control group (video

38 documentary or factsheet not related to PPD). Results showed that there were no effects for type

39 of intervention on either personal or perceived PPD stigma scores. No effect was found for help-

40 seeking propensity. Males had higher personal PPD stigma than females and older age was

41 associated with lower personal PPD stigma. Familiarity with PPD was associated with perceived

42 PPD stigma in others but not personal PPD stigma. More work needs to be conducted to develop

43 interventions to reduce PPD stigma in the community. 
burden of disease (Prince et al., 2007; Vigo, Thornicroft, \& Atun, 2016). According to the World Health Organization (2017), depression is the leading cause of disability worldwide.

Accordingly, depression and anxiety are the most prevalent mental disorders experienced by

Australians (Australian Bureau of Statistics, 2008 [ABS]). The present study focuses specifically on postpartum depression (PPD). One Australian study found that at 6 months postpartum the proportion of women reporting symptoms was, $17.4 \%$ for depression, $12.7 \%$ for anxiety, and $8.1 \%$ for both anxiety and/or depression (Yelland, Sutherland, \& Brown, 2010). These proportions are even higher if the period prevalence is used (Austin et al., 2010; Wynter, Rowe, \& Fisher, 2013). Given that over 300,000 women give birth annually in Australia (Australian Institute of Health and Welfare, 2018), it is estimated that PPD affects approximately 66,000 women each year.

Individuals with a depressive illness have to not only manage their symptoms but also cope with the stigma and discrimination these conditions receive. Stigma has a large impact on help-seeking behaviours with research indicating that many sufferers choose not to pursue treatment so as to avoid the label of 'mental illness' and the discrimination associated with such a label (Barney et al., 2006; Byrne, 2000; Corrigan, 2004).

\section{Postpartum Depression}

The Diagnostic and Statistical Manual of Mental Disorders - 5 (DSM-5; American Psychiatric Association, 2013) lists peripartum onset as a specifier for a major depressive episode. PPD is based on the same diagnostic criteria as a major depressive episode, but with the 
70 onset of symptoms (e.g., negative mood, sleep disturbance, significant changes in appetite, poor

71 concentration, and loss of interest or pleasure) occurring during the last month of gestation or the

72 first several months after delivery. The likelihood of suffering PPD is high. For example, in a

73 study of 243 women who had recently given birth (Jackman, Thorsteinsson, \& McNeil, 2017),

74 results found that $44 \%$ of the sample met the criteria for either likely (30\%) or possible (14\%)

75 PPD as measured by the Edinburgh Postnatal Depression Scale (Cox, Holden, \& Sagovsky,

76 1987). PPD can range in severity from mild to severe and symptoms can begin suddenly after the

77 birth of a child or appear gradually in the weeks or months during the first year after birth (Bobo

78 \& Yawn, 2014). Maternal or paternal PPD can have devastating effects on children and can lead

79 to disturbances in children's social, behavioural, cognitive, and physical development

80 (Ramchandani et al., 2005; Ramchandani et al., 2008).

\section{Stigma}

82 According to Goffman (1963 p. 3), stigma refers to "an attribute that is deeply

83 discrediting" and, as such, is generally "linked with illnesses or conditions that are believed to be

84 under the individual's control or manifested as a consequence of unacceptable social behavior"

85 (Pinto-Foltz \& Logsdon, 2008, pp. 21-22). When stigma occurs, a person is labelled by their

86 illness and viewed as part of a stereotyped group (Corrigan, 2004). Stigmas are defined as having

87 three elements - problems of knowledge (ignorance or misinformation, e.g., a belief that

88 someone is dangerous); problems of attitudes (prejudice that may lead to emotional reactions,

89 e.g., fearing someone because of the belief that someone is dangerous); and problems of

90 behaviour (discrimination, e.g., avoiding someone with depression Thornicroft et al., 2007).

91 There are also different types of stigma including personal (i.e., own beliefs about other people)

92 and perceived (i.e., expectations of others' beliefs; Griffiths et al., 2004); self (i.e., stigmatising 
93 views held about the self; Corrigan \& Watson, 2002), and structural (i.e., policies that restrict the

94 opportunities, resources, and wellbeing of people with depression; Corrigan, Markowitz, \&

95 Watson, 2004). Notably, personal and perceived stigma are thought to strongly influence an

96 individual's help-seeking behaviour (Barney et al., 2006; Corrigan et al., 2003) and are the focus

97 of the present study.

98 Familiarity

Familiarity with mental illness is highly correlated with stigma. Familiarity is described

100 as the knowledge of and experience with mental illness (Corrigan et al., 2003). Familiarity can

101 be viewed on a continuum of intensity from viewing portrayals of mental illness on television, to

102 having a friend with a mental illness, to having a mental illness oneself. Research shows that

103 higher familiarity reduces stigma and stereotyping towards persons with a mental illness (Calear,

104 Griffiths, \& Christensen, 2011; Corrigan, 2004). Familiarity has previously been captured

105 through recognition (a measure of knowledge of PPD) and reported as higher than $70 \%$

106 (Thorsteinsson, Loi, \& Moulynox, 2014).

107 Stereotypes

108 Stigmas are also closely linked with stereotypes. Stereotypes are described as knowledge

109 structures that the public collectively holds about a specific social group (Corrigan, 2004).

110 Common stereotypes regarding people with a mental illness tend to be negative and include

111 violence (e.g., "people with a mental illness are dangerous"), incompetence (e.g., "people with a

112 mental illness are unable to look after themselves"), and blame (e.g., "people with a mental

113 illness are weak and are responsible for their disorder"; Barney et al., 2006; Cornally \&

114 McCarthy, 2011). Stereotyping leads to prejudice which in turn leads to discrimination towards

115 individuals with a mental illness (Corrigan, 2004; Reavley \& Jorm, 2011). 
117 individuals who hold high levels of stigma. Griffiths, Christensen, and Jorm (2008) found that

118 personal stigma was higher among males and the elderly. Similarly, Calear et al. (2011) found

119 that personal depression stigma was predicted by being male and having no personal or parental

120 history (i.e., familiarity) of depression.

\section{Help-Seeking Behaviours}

From a mental health perspective, help-seeking is defined as a flexible coping process

123 that involves obtaining external assistance to treat a mental health concern (Rickwood, Thomas,

124 \& Bradford, 2013). Despite the high incidence of mental illness in Australia, the majority of

125 sufferers do not access professional help services. Studies show that among individuals suffering

126 from a mental illness, up to $65 \%$ do not consult mental health professionals, resulting in a

127 distinct variance between the prevalence of illness and the extent of professional help-seeking

128 (ABS, 2008; Rickwood et al., 2013).

129 Research shows that help-seeking behaviour may be inhibited if other members of the

130 community are perceived as holding negative stigmas (Corrigan \& Watson, 2002; Dew et al.,

131 1988; Vogel et al., 2007). Recently, the topic of help-seeking behaviours has gained popularity

132 as researchers attempt to explore and understand individuals' delayed responsive actions to

133 symptoms of illness across a variety of health conditions.

\section{Challenging Stigma and Improving Help-Seeking Behaviour}

135 PPD is often left untreated as women frequently report feeling ashamed about seeking

136 help, and hold concerns about being branded a 'bad mother' if they acknowledge that they are

137 battling depression (Saporito, Ryan, \& Teachman, 2011). Effective anti-stigma strategies include

138 education (e.g., challenging the myths of mental illness with factual information); protest (e.g., 
139 making moral appeals to stop stigmatisation); and contact (e.g., creating equal interactions

140 between the public and individuals with a mental illness; Corrigan et al., 2003; Griffiths et al.,

141 2014). Griffiths et al. (2004) found that brief targeted education programs involving web-based

142 literacy (i.e., BluePages; The Australian National University, 2018) and cognitive-behavioural

143 interventions (i.e., moodgym; ehubHealth, 2018) were effective in reducing levels of depression

144 stigma.

145 To date there has been some research interest in depression-related stigma (e.g., Barney

146 et al., 2006; Byrne, 2000; Griffiths et al., 2014). However, few studies have addressed PPD

147 stigma. Research has found that knowing someone with depression is associated with less

148 stigmatising attitudes (Corrigan \& Watson, 2007; Griffiths et al., 2008). Targeted education

149 programs that teach individuals that mental disorders are an illness like any other have been

150 shown to be effective (Corrigan \& Watson, 2007).

\section{The Present Study}

152 Given the lack of research on depression stigma, the aim of the current study was to

153 examine existing levels of personal and perceived depression stigma among a sample of parents

154 to determine if targeted intervention materials (i.e., factsheet and documentary) can reduce levels

155 of depression stigma. Based on the literature discussed, it was hypothesised that (1) an education

156 intervention would influence depression stigma and help-seeking behaviour scores. Specifically,

157 the participants in the PPD factsheet or video documentary groups would have lower depression

158 stigma and higher help-seeking behaviour scores (pre-test versus post-test measures) compared

159 to the control groups (i.e., family documentary or raising children factsheet); (2) levels of

160 familiarity with PPD would be inversely correlated with levels of both personal and perceived 
161 stigma; and (3) males and older persons would have higher levels of personal PPD stigma than

162 females and younger persons, respectively.

\section{Method}

\section{Participants}

165 The study was accessed by 594 participants. However, due to an incompatibility between

166 the software platform and video usage on smartphones, tablets, and some web browsers, a

167 majority of the participants $(n=373 ; 62.8 \%)$ were unable to complete the survey. A further nine

168 participants were eliminated from the study due to incomplete questionnaires. Therefore, useable

169 data (Thorsteinsson, Loi, \& Farr, 2018) was obtained from 212 participants (35.7\% retention

170 rate) aged between 18 and 71 years $(M=36.88, S D=8.71)$. An a priori power analysis showed that

171192 participants would be needed assuming a low-medium effect size (Hedges' $g$ ) of 0.28 (based

172 on the findings of Griffiths et al., 2014), a low-medium effect size $(d)$ of 0.28 was anticipated for

173 the current study. to achieve power $=.80$ (Faul et al., 2007).

174 To be included in the study, participants were required to have one or more children. The

175 final sample comprised 18 males (8.5\%) and 194 females (91.5\%). A large proportion of

176 participants $(72.1 \%)$ had one to two children, with $27.9 \%$ of participants having three or more

177 children. The majority of participants held a bachelor's degree or higher $(n=120,56.6 \%)$. A

178 considerable proportion $(n=34 ; 16 \%)$ of participants had medical or allied health training. Table

1791 shows demographics within each intervention group.

180 Measures

181 The online self-report questionnaire battery consisted of 116 questions. All participants in

182 the study completed a pre-intervention questionnaire that included a variety of sociodemographic 183 and illness exposure measures. The sociodemographic variables collected included sex and age. 
184 The illness exposure variables measured included history of personal PPD, history of personal

185 mental illness, family member/friend history of PPD, family member/friend history of mental

186 illness, and current confidante/s to discuss mental health concerns. Familiarity with PPD was

187 measured with one question "Have you personally experienced postnatal depression?" answered

188 either as $0(\mathrm{No})$ or 1 (Yes).

189 Personal and perceived PPD stigma. Personal and perceived PPD stigma was measured

190 using the Depression Stigma Scale (DSS; Griffiths et al., 2004) with the wording modified to

191 include the word "postnatal" Postnatal was used rather than postpartum as the former was

192 considered a better match to then community knowledge. The 18-item scale assesses

193 stigmatising attitudes and beliefs toward individuals with PPD and consists of two subscales:

194 personal stigma and perceived stigma. The personal stigma subscale assesses the participant's

195 own attitudes towards individuals with PPD (9 items: e.g., "People with postnatal depression are

196 unpredictable"), while the perceived stigma subscale assesses the participant's perception of the

197 attitudes of others to individuals with PPD (9 items: e.g., "Most people believe that people with

198 postnatal depression are unpredictable"). Items on each of the subscales are rated on a 5-point

199 Likert scale ranging from 0 (strongly disagree) to 4 (strongly agree). A total scale score is

200 calculated by summing item scores, with total scale scores ranging from 0 to 72 . Higher scores

201 are indicative of greater stigma. The two subscales have been reported as having moderate to

202 high internal consistency ( $\alpha=.72$ to .82; Griffiths et al., 2008; Griffiths et al., 2004), and

203 moderate test-retest reliability (Griffiths et al., 2004). In the present study, a moderate level of

204 internal consistency was attained, with a McDonald's omega of .81 for personal PPD stigma and

205.90 for perceived PPD stigma. 
Attitudes towards help-seeking. Attitudes towards help-seeking for treatment of a

207 mental health issue was assessed using the Inventory of Attitudes toward Seeking Mental Health

208 Services Scale (IASMHS; Mackenzie et al., 2004). The IASMHS is a 24-item instrument that

209 measures beliefs about seeking professional help for mental health problems. Items are presented

210 on a 5-point Likert scale ranging from 0 (strongly disagree) to 4 (strongly agree), with high

211 scores reflecting more positive attitudes. The scale comprises three subscales: psychological

212 openness (8 items: e.g., "Psychological problems, like many things, tend to work out by

213 themselves"); help-seeking propensity (8 items: e.g., "I would want to get professional help if I

214 were worried or upset for a long period of time"); and indifference to stigma (8 items: e.g.,

215 "Having been mentally ill carries with it a burden of shame"). Higher total scores indicate a more

216 positive attitude toward seeking help. In the current study, a moderate level of internal

217 consistency was attained based on McDonald's omega, with.77 for psychological openness .76

218 for help-seeking propensity, and .83 for indifference to stigma.

\section{Intervention Groups}

Using Qualtrics software, participants were randomly assigned to one of four intervention

221 groups, see Figure 1.

Experimental factsheet group. Participants in this group were shown a digital factsheet

written by the Post and Antenatal Depression Association (PANDA) and used with permission

224 from the Chief Executive Officer (B. Horton; personal communication, March 25, 2014). The

225 factsheet spanned two pages and contained information outlining the contributing factors,

226 common symptoms, and potential treatments of PPD.

Control factsheet group. Participants in this group were shown an electronic factsheet compiled by the Raising Children Network (2006) and used with permission from the secretary 
229 of the network (Network Secretary, personal communication, April 2, 2014). The factsheet

230 contained information about parenting, the challenges of being a parent, and tips to deal with

231 parenting difficulties. The factsheet was designed to be generic, therefore to control for the

232 effects of the term postpartum depression used in the experimental factsheet group, the control

233 group's factsheet did not contain any references to PPD.

234 Experimental documentary group. Participants in this group were required to view a

235 documentary produced by PANDA and used with permission (B. Horton; personal

236 communication, March 25, 2014). The documentary ran for $8 \min 38 \mathrm{sec}$ and outlined the burden

237 of PPD, gave real-life experiences of sufferers of PPD and their families, and included insights

238 into the illness from experts and health professionals.

239 Control documentary group. Participants in this group were required to view a

240 documentary comprising five "Meet the Families" video clips taken from the Raising Children

241 Network website (www.raisingchildren.net.au). These clips were used with permission (Network

242 Secretary, personal communication, April 2, 2014). The duration of the documentary was $7 \mathrm{~min}$

24355 secs and depicted the stories of five families and their experiences of raising children. To

244 control for the effects of the term postpartum depression used in the experimental documentary

245 group, this documentary did not contain any references to PPD.

246 Procedure

247 Ethical approval for the study was obtained from the University of New England's

248 Human Research Ethics Committee (Approval Number: HE14-154). A pilot study was

249 implemented to check for clarity of questions and the effects of question order. Three questions

250 were reworded when they were identified as being difficult to comprehend. No order effects

251 were found for question order and thus question presentation remained unchanged. 
253 forums (e.g., Reddit), and the university's online learning platform. The study was administered

254 through Qualtrics (Provo, UT), a secure online survey site. Participants were provided with an

255 information sheet fully informing them of the purpose of the study. They were then advised that

256 their responses were anonymous and that withdrawal from the study was permitted at any time

257 without consequence. Participants were also informed that activation of the "Proceed to study"

258 button constituted their informed consent.

Participants were asked demographic and illness exposure questions before the DSS and

260 IASMHS were presented. Employing a randomised control trial study design, participants were

261 randomly assigned to one of the four intervention groups. At the conclusion of the intervention,

262 participants were once again required to complete the DSS and IASMHS. At the close of the

263 survey, participants were thanked for their time and invited to enter an optional prize draw for a

264 chance to win an AUD\$50 iTunes gift card. Participants were then redirected to the PANDA

265 website where they could find further information about PPD.

266 Manipulation Checks

267 At the end of the intervention, all participants were asked three questions about the

268 intervention: "How effective were the resources in improving your knowledge and understanding

269 of postnatal depression?", "How effective were the resources in improving the likelihood that

270 you would seek professional help for a psychological problem?", and "How effective were the

271 resources in improving the likelihood that you would encourage others to seek professional help

272 for a psychological problem?”. These questions were answered on a scale from 1 (resources

273 were poor) to 5 (resources were excellent). The two experimental groups were rated significantly

274 higher than the two control groups on all three questions by the participants, see Table 1. 
275 Statistical Analysis

276 Statistical analyses were performed using SPSS (versions 24 and 25) and JASP (version

277 0.8.6.0). Missing values were replaced using the replace missing values, series mean method.

278 Selected questions were reverse scored in line with measurement requirements. As all

279 assumptions of normality were met, raw data was employed in the following analyses. A one-

280 way analysis of covariance (ANCOVA) was used to examine the impact of intervention groups

281 on personal and perceived PPD stigma and help-seeking behaviour scores. Pre-intervention

282 levels of PPD stigma and help-seeking were employed as covariates.

283

\section{Results}

\section{Intervention}

285

The ANCOVA showed that following the intervention, personal PPD stigma scores

286

differed between the four groups, $F(3,207)=3.05, p=.030$, partial $\eta^{2}=.04$. However, there were no

287 statistically significant pairwise comparison effects. Furthermore, Table 2 shows that the

288 intervention did not reduce personal PPD stigma.

289 The pattern of findings for perceived PPD stigma did not indicate a statistically

290 significant difference, $F(3,207)=2.19, p=.090$, partial $\eta^{2}=.03$. There were no significant pairwise

291 comparison and perceived PPD stigma increased from pre- to post-test, see Table 2.

292 The results for help-seeking propensity were not affected by the intervention,

$293 F(3,207)=1.15, p=.332$, partial $\eta^{2}=.02$, see Table 2 .

294 Sex, Age, and Familiarity with PPD

295 Post-intervention personal PPD stigma was used in the following analysis, but results

296 were almost the same for pre-intervention personal PPD stigma. Males had higher personal PPD

297 stigma $(M=10.11, S D=4.75)$ than females $(M=7.21, S D=4.50), t(210)=2.61, p=.010$, Hedges' $g=$ 
298

299

300

301

302

303

304

305

306

307

308

309

310

311

312

313

314

315

316

317

318

319

320

$0.64,95 \%$ CI $[0.15,1.13]$. Age was associated with personal PPD stigma, $r(210)=-.18, p=.010$, thus the older the participant the less their personal PPD stigma. Familiarity $(n o=0, y e s=1)$ with PPD was correlated with post-intervention perceived PPD stigma scores, $r(210)=.21, p<.01$ but not with post-intervention personal PPD stigma scores, $r(210)=.01, p=.839$. Reclassifying familiarity to include both personal familiarity and familiarity through friends or relations also resulted in low correlations ( $r=-.01$ and $r=.06$, respectively). A multiple regression with sex, age, and familiarity as predictors explained only $3.2 \%\left(R^{2}\right)$ of the variance in post-intervention personal PPD stigma scores, $F(3,208)=2.31, p=.077$. The same predictors only explained $0.6 \%\left(R^{2}\right)$ in post-intervention perceived PPD stigma scores.

\section{Post hoc Analysis}

An additional analysis examining the relationship between personal familiarity and helpseeking was conducted. Results revealed a significant effect of familiarity on attitudes towards help-seeking scores, $F(1,209)=4.31, p=.039$, partial $\eta^{2}=.02$. Participants with a personal experience of PPD had more negative attitudes towards help-seeking $(M=64.39, S D=12.28)$ compared to participants with no personal experience of PPD $(M=68.97, S D=12.37)$.

\section{Discussion}

This study sought to examine how an education intervention would impact PPD stigma and, more indirectly, help-seeking propensity.

\section{Education Intervention and Help-seeking}

It was hypothesised that an education intervention would significantly influence PPD stigma scores. Specifically, that participants in the intervention groups (factsheet or video) would have lower personal and perceived PPD stigma and higher help-seeking scores compared to the control groups. Results, however, revealed that the intervention had no significant effect on PPD 
321 stigma scores. These findings are inconsistent with previous findings (Corrigan et al., 2003;

322 Griffiths et al., 2004) demonstrating that educational interventions could significantly reduce

323 personal and perceived stigma. One reason for these inconsistent findings is that previously used

324 interventions tended to be more interactional. That is, participants were required to perform a

325 type of action. As participants in the present study were simply required to watch a video or read

326 a factsheet, they may not have engaged as much with the material. Another suggestion for these

327 inconsistent findings is that group sizes in previous studies tended to be much larger $(n=165$;

328 Griffiths et al., 2004) than the present study ( $n=53)$. Future studies may benefit from including

329 several overt manipulation checks throughout the survey to confirm that the intervention groups

330 were successfully manipulated.

331 We anticipated that viewing a PPD documentary would lead to increased help-seeking

332 behaviours. Results showed that there was no significant effect of type of intervention on help-

333 seeking propensity.

\section{Sex and Age}

335 Consistent with previous research (e.g., Calear et al., 2011; Corrigan, 2004), males had

336 higher levels of personal PPD stigma than females. Additionally, we hypothesised that older

337 persons would have higher levels of personal stigma, however, this was not supported. While age

338 was associated with personal PPD stigma, the results indicated that the older the participant, the

339 lower their levels of personal PPD stigma. This result is inconsistent with previous research

340 conducted by Corrigan et al. (2003) who found that older persons exhibited more personal

341 stigma towards individuals with depression. One explanation for these varied findings is that the

342 older aged participants in the current study may have had high levels of familiarity with PPD. It 
343 is quite possible that their own child may have experienced PPD and this may have influenced

344 their personal PPD stigma levels.

345 Familiarity

346 Inconsistent with previous research, familiarity was positively correlated with perceived

347 PPD stigma scores rather than inversely (Corrigan, 2004; Griffiths et al., 2004). Unexpectedly,

348 participants who had personally experienced PPD had significantly higher perceived stigma

349 scores. The results of the current study suggest that individuals who have experienced PPD

350 expect that other people will hold higher levels of stigma towards people with PPD. Perceived

351 stigma has been shown to negatively affect help-seeking behaviours (Corrigan \& Watson, 2002).

352 If those experiencing PPD do anticipate high levels of stigma in the community, this could

353 greatly impact their help-seeking behaviours, leading to cases of PPD being left undiagnosed and

354 untreated. An alternative explanation for these results could be that individuals who have

355 experienced PPD are quite sensitive about the topic and unwittingly overinflated the expected 356 negative attitudes of others.

357 Familiarity with PPD was not associated with the participants' own stigma towards

358 people with PPD (personal PPD). It is unclear why familiarly with PPD does not reduce the

359 participants' own stigma towards PPD. Any relationship between familiarly with PPD and

360 personal PPD stigma may be 'hidden' by the type of familiarity, thus future research may want

361 to ask questions that assess the type of familiarity in more detail than in the present study.

\section{Limitations and Future Research}

363 The participants were predominantly female and educated and this should be taken into

364 account when considering generalising the findings to the broader community. A larger sample

365 of males is needed to enable a reliable comparison with females given that males tend to have a 
366 worse mental health literacy than females (Gibbons, Thorsteinsson, \& Loi, 2015). The sample is

367 also biased towards participants with medical or allied health training (i.e., 16\%), potentially as a

368 result of a low retention rate. Furthermore, future studies might like to sample from a population

369 of pregnant women or women wanting to be pregnant and their partners as they are the

370 population at risk of PPD.

371 Further research is needed to fully understand the different types of stigma that are

372 associated with PPD and any social, sex, and age factors that may underlie it. Research of a

373 longitudinal nature is also required to investigate if changes in attitudes lead to changes in

374 behaviour. Of specific interest is whether a targeted intervention can effectively reduce personal

375 and/or perceived stigma levels and lead to a change in behaviour toward individuals with PPD.

376 Such interventions could include clear hospital guidelines such as have been successful in

377 increasing individuals' psychological wellbeing (Basile \& Thorsteinsson, 2015).

\section{Conclusions}

379 It is apparent that stigmatising beliefs and attitudes regarding PPD do exist in the 380 parenting community. Stigma towards people with PPD (personal stigma) was predicted by

381 being male and being younger. Personal familiarity with PPD increased people's expectations

382 that there would be stigma towards those with PPD. The stigma intervention was not effective in

383 the present study suggesting that such interventions need to be developed differently. It may be

384 appropriate to develop a broader-based education program targeting attitudes, disorder

385 characteristics, and effects of stigma for the general parenting community. 
American Psychiatric Association. (2013). Diagnostic and statistical manual of mental disorders (5th ed.). Washington, DC: Author.

Austin, M.-P. V., Hadzi-Pavlovic, D., Priest, S. R., Reilly, N., Wilhelm, K., Saint, K., \& Parker, G. (2010). Depressive and anxiety disorders in the postpartum period: How prevalent are they and can we improve their detection? Archives of Women's Mental Health, 13, 395401. doi:10.1007/s00737-010-0153-7

Australian Bureau of Statistics. (2008). National survey of mental health and wellbeing: Summary of results 2007. Cat no. 4326.0. Retrieved from

Australian Institute of Health and Welfare. (2018). Australia's mothers and babies 2016 - in brief. Retrieved from https://www.aihw.gov.au/getmedia/7a8ad47e-8817-46d3-975744fe975969c4/aihw-per-97.pdf.aspx?inline=true.

Barney, L. J., Griffiths, K. M., Jorm, A. F., \& Christensen, H. (2006). Stigma about depression and its impact on help-seeking intentions. Australian and New Zealand Journal of Psychiatry, 40, 51-54. doi:10.1111/j.1440-1614.2006.01741.x

Basile, M. L., \& Thorsteinsson, E. B. (2015). Parents' evaluation of support in Australian hospitals following stillbirth. PeerJ, 3, e1049. doi:10.7717/peerj.1049

Bobo, W. V., \& Yawn, B. P. (2014). Concise review for physicians and other clinicians: Postpartum depression. Mayo Clinic Proceedings, 89, 835-844. doi:10.1016/j.mayocp.2014.01.027 
408 Byrne, P. (2000). Stigma of mental illness and ways of diminishing it. Advances in Psychiatric 409 Treatment, 6, 65-72. doi:10.1192/apt.6.1.65

410 Calear, A. L., Griffiths, K. M., \& Christensen, H. (2011). Personal and perceived depression 411 stigma in Australian adolescents: Magnitude and predictors. Journal of Affective

412 Disorders, 129, 104-108. doi:10.1016/j.jad.2010.08.019

413 Cornally, N., \& McCarthy, G. (2011). Help-seeking behaviour: A concept analysis. Journal of 414 Nursing Practice, 17, 280-288. doi:10.1111/j.1440-172X.2011.01936.x

415 Corrigan, P. (2004). How stigma interferes with mental health care. American Psychologist, 59, 416 614-625. doi:10.1037/0003-066x.59.7.614

417 Corrigan, P., Markowitz, F. E., \& Watson, A. C. (2004). Structural levels of mental illness stigma and discrimination. Schizophrenia Bulletin, 30, 481-491. doi:10.1093/oxfordjournals.schbul.a007096

Corrigan, P., \& Watson, A. C. (2007). The stigma of psychiatric disorders and the gender, 421 ethnicity, and education of the perceiver. Community Mental Health Journal, 43, 439458. doi:10.1007/s10597-007-9084-9

423

424

425 426 427 428 429 430

Corrigan, P. W., Markowitz, F. E., Watson, A., Rowan, D., \& Kubiak, M. A. (2003). An attribution model of public discrimination towards persons with mental illness. Journal of Health and Social Behavior, 44, 162-179. doi:10.2307/1519806

Corrigan, P. W., \& Watson, A. C. (2002). The paradox of self-stigma and mental illness. Clinical Psychology - Science and Practice, 9, 35-53. doi:10.1093/clipsy.9.1.35

Cox, J. L., Holden, J. M., \& Sagovsky, R. (1987). Detection of postnatal depression: Development of the 10-item Edinburgh Postnatal Depression Scale. British Journal of Psychiatry, 150, 782-786. doi:10.1192/bjp.150.6.782 
431 Dew, M. A., Dunn, L. O., Bromet, E. J., \& Schulberg, H. C. (1988). Factors affecting help432 seeking during depression in a community sample. Journal of Affective Disorders, 14, 433 223-234. doi:10.1016/0165-0327(88)90038-9

434 435 436

ehubHealth. (2018). moodgym. Retrieved from https://moodgym.com.au/

Faul, F., Erdfelder, E., Lang, A. G., \& Buchner, A. (2007). G*Power 3: A flexible statistical power analysis program for the social, behavioral, and biomedical sciences. Behavior Research Methods, 39, 175-191. doi:10.3758/BF03193146

Gibbons, R. J., Thorsteinsson, E. B., \& Loi, N. M. (2015). Beliefs and attitudes towards mental illness: An examination of the sex differences in mental health literacy in a community sample. PeerJ, 3, e1004. doi:10.7717/peerj.1004

Goffman, E. (1963). Stigma: Notes on the management of spoiled identity. Englewood Cliffs, NJ: Prentice-Hall.

Griffiths, K. M., Carron-Arthur, B., Parsons, A., \& Reid, R. (2014). Effectiveness of programs for reducing stigma associated with mental disorders: A meta-analysis of randomized controlled trials. World Psychiatry, 13, 161-175. doi:10.1002/wps.20129

Griffiths, K. M., Christensen, H., \& Jorm, A. F. (2008). Predictors of depression stigma. BMC Psychiatry, 8, 25. doi:10.1186/1471-244X-8-25

Griffiths, K. M., Christensen, H., Jorm, A. F., Evans, K., \& Groves, C. (2004). Effect of webbased depression literacy and cognitive-behavioural therapy interventions on stigmatising attitudes to depression: Randomised controlled trial. The British Journal of Psychiatry, 185, 342-349. doi:10.1192/bjp.185.4.342 
452 Jackman, L., Thorsteinsson, E. B., \& McNeil, D. (2017). Perfect imperfections: Locus of control, 453 perfectionism and postpartum depression. SAGE Open, 7, 1-8.

454 doi:10.1177/2158244017710689

455

456

457

458

459

460

461

462

463

464

465

466

467

468

469

470

471

472

473

474

Mackenzie, C. S., Knox, V. J., Gekoski, W. L., \& Macaulay, H. L. (2004). An adaptation and extension of the Attitudes toward Seeking Professional Psychological Help Scale. Journal of Applied Social Psychology, 34, 2410-2435. doi:10.1111/j.15591816.2004.tb01984.x

Pinto-Foltz, M. D., \& Logsdon, M. C. (2008). Stigma towards mental illness: A concept analysis using postpartum depression as an example. Issues in Mental Health Nursing, 29, 21-36. doi:10.1080/01612840701748698

Post and Antenatal Depression Association. (2017). Retrieved from https:/www.panda.org.au/

Prince, M., Patel, V., Saxena, S., Maj, M., Maselko, J., Phillips, M. R., \& Rahman, A. (2007). No health without mental health. Lancet, 370, 859-877. doi:10.1016/S01406736(07)61238-0

Ramchandani, P., Stein, A., Evans, J., \& O'Connor, T. G. (2005). Paternal depression in the postnatal period and child development: A prospective population study. The Lancet, 365, 2201-2205. doi:10.1016/S0140-6736(05)66778-5

Ramchandani, P. G., Stein, A., O'Connor, T. G., Heron, J., Murray, L., \& Evans, J. (2008). Depression in men in the postnatal period and later child psychopathology: A population cohort study. Journal of the American Academy of Child \& Adolescent Psychiatry, 47, 390-398. doi:10.1097/CHI.0b013e31816429c2

Reavley, N. J., \& Jorm, A. F. (2011). Stigmatizing attitudes towards people with mental disorders: Findings from an Australian national survey of mental health literacy and 
475

476

477

478

479

480

481

482

483

484

485

486

487

488

489

490

491

492

493

494

495

496

497

stigma. Australian and New Zealand Journal of Psychiatry, 45, 1086-1093.

doi:10.3109/00048674.2011.621061

Rickwood, D., Thomas, K., \& Bradford, S. (2013). Help-seeking measures in mental health: A rapid review. Retrieved from https://www.saxinstitute.org.au/ publications/help-seekingmeasures-in-mental-health-a-rapid-review/

Saporito, J. M., Ryan, C., \& Teachman, B. A. (2011). Reducing stigma toward seeking mental health treatment among adolescents. Stigma Research and Action, 2, 9-21. doi:10.5463/SRA.v1i1.2

The Australian National University. (2018). BluePages: Depression information. Retrieved from https://bluepages.anu.edu.au/

Thornicroft, G., Rose, D., Kassam, A., \& Sartorius, N. (2007). Stigma: Ignorance, prejudice or discrimination? British Journal of Psychiatry, 190, 192-193. doi:10.1192/bjp.bp.106.025791

Thorsteinsson, E. B., Loi, N. M., \& Moulynox, A. L. (2014). Mental health literacy of depression and postnatal depression: A community sample. Open Journal of Depression, 3, 101-111. doi:10.4236/ojd.2014.33014

Vigo, D., Thornicroft, G., \& Atun, R. (2016). Estimating the true burden of mental illness. Lancet Psychiatry, 3, 171-178. doi:10.1016/S2215-0366(15)00505-2

Vogel, D. L., Wade, N. G., Wester, S. R., Larson, L., \& Hackler, A. H. (2007). Seeking help from a mental health professional: The influence of one's social network. Journal of Clinical Psychology, 63, 233-245. doi:10.1002/jclp.20345

World Health Organization. (2017). Depression. Retrieved from http://www.who.int/mediacentre/factsheets/fs369/en/ 
498 Wynter, K., Rowe, H., \& Fisher, J. (2013). Common mental disorders in women and men in the 499 first six months after the birth of their first infant: A community study in Victoria, $500 \quad$ Australia. Journal of Affective Disorders, 151, 980-985. doi:10.1016/j.jad.2013.08.021

501 Yelland, J., Sutherland, G., \& Brown, S. J. (2010). Postpartum anxiety, depression and social 502 health: Findings from a population-based survey of Australian women. BMC Public $503 \quad$ Health, 10. doi:10.1186/1471-2458-10-771 


\section{Table 1 (on next page)}

Participant demographics and manipulation checks 
$1 \quad$ Table 1

2 Participant Demographics and Manipulation Checks

\begin{tabular}{|c|c|c|c|c|c|}
\hline \multirow[b]{3}{*}{ Measure } & \multicolumn{4}{|c|}{ Condition } & \multirow[b]{3}{*}{ Statistical comparison } \\
\hline & \multicolumn{4}{|l|}{ Experimental } & \\
\hline & $\begin{array}{c}\text { video } \\
\text { documentary }\end{array}$ & $\begin{array}{l}\text { Control video } \\
\text { documentary }\end{array}$ & $\begin{array}{l}\text { Experimental } \\
\text { factsheet }\end{array}$ & $\begin{array}{l}\text { Control } \\
\text { factsheet }\end{array}$ & \\
\hline$n$ & 42 & 50 & 58 & 62 & $\chi^{2}(3, N=212)=4.45, p=.217$ \\
\hline Sex $[n$ males/females $]$ & $5 / 37$ & $5 / 45$ & $2 / 56$ & $6 / 56$ & $\chi^{2}(3, N=212)=2.79, p=.426$ \\
\hline Age $[M(S D)]$ & $39.88_{a}(11.02)$ & $36.70_{\mathrm{ab}}(9.08)$ & $35.02_{\mathrm{b}}(7.42)$ & $36.73_{\mathrm{ab}}(7.32)$ & $F(3,212)=2.62, p=.052$ \\
\hline Education $[n]$ & $4 / 6 / 6 / 19 / 7$ & $2 / 4 / 13 / 22 / 9$ & $3 / 8 / 18 / 18 / 11$ & $3 / 5 / 20 / 22 / 12$ & $\chi^{2}(4, N=212)=5.94, p=.203$ \\
\hline Medical or allied health training [ $n$ Yes/No] & $6 / 36$ & $8 / 42$ & $8 / 50$ & $12 / 50$ & $\chi^{2}(3, N=212)=0.82, p=.845$ \\
\hline \multicolumn{6}{|l|}{ Intervention improved: $[M(S D)]$} \\
\hline Knowledge of PPD & $4.18_{\mathrm{a}}(0.68)$ & $2.26_{\mathrm{b}}(1.26)$ & $4.04_{a}(0.93)$ & $3.23_{\mathrm{c}}(1.18)$ & $F(3,196)=33,13, p<.001$ \\
\hline Likelihood seek professional help & $4.00_{\mathrm{a}}(0.93)$ & $2.37_{\mathrm{c}}(1.32)$ & $3.71_{\mathrm{a}}(1.17)$ & $3.06_{\mathrm{b}}(1.20)$ & $F(3,180)=23.12, p<.001$ \\
\hline $\begin{array}{l}\text { Likelihood encourage others to seek } \\
\text { professional help }\end{array}$ & $4.32_{\mathrm{a}}(0.78)$ & $2.47_{\mathrm{c}}(1.42)$ & $4.29 \mathrm{a}(0.65)$ & $3.45_{b}(1.19)$ & $F(3,176)=29.37, p<.001$ \\
\hline
\end{tabular}




\section{Table 2 (on next page)}

Means and standard deviations for assessment of postpartum Stigma by experimental condition 
1 Table 2

2 Means and Standard Deviations for Assessment of Postpartum Stigma by Experimental

3 Condition

\begin{tabular}{lcccc}
\hline & \multicolumn{2}{c}{ Condition } \\
\cline { 2 - 5 } & $\begin{array}{c}\text { Experimental } \\
\text { video }\end{array}$ & $\begin{array}{c}\text { Control video } \\
\text { Measure }\end{array}$ & $\begin{array}{c}\text { Experimental } \\
\text { focumentary }\end{array}$ & $\begin{array}{c}\text { Control } \\
\text { focumentary }\end{array}$ \\
\hline$n$ & 42 & 50 & 58 & 62 \\
Pre-intervention Personal & $6.21(4.37)$ & $7.12(4.81)$ & $6.48(4.38)$ & $6.92(4.01)$ \\
Post-intervention Personal & $6.31(4.36)$ & $7.39(4.81)$ & $7.79(4.64)$ & $7.97(4.47)$ \\
Pre-intervention Perceived & $17.64(5.05)$ & $18.04(7.01)$ & $16.48(7.58)$ & $16.81(6.59)$ \\
Post-intervention Perceived & $18.29(5.33)$ & $18.90(6.57)$ & $16.08(7.77)$ & $17.65(6.71)$ \\
Pre-intervention help-seeking & $2.96(0.57)$ & $2.87(0.52)$ & $2.96(0.54)$ & $2.87(0.49)$ \\
propensity & & & & \\
Post-intervention help- & $3.04(0.48)$ & $2.85(0.55)$ & $2.97(0.65)$ & $2.89(0.53)$ \\
seeking propensity & & & & \\
\hline
\end{tabular}

4 


\section{Figure 1 (on next page)}

Flow diagram showing randomization of participants 


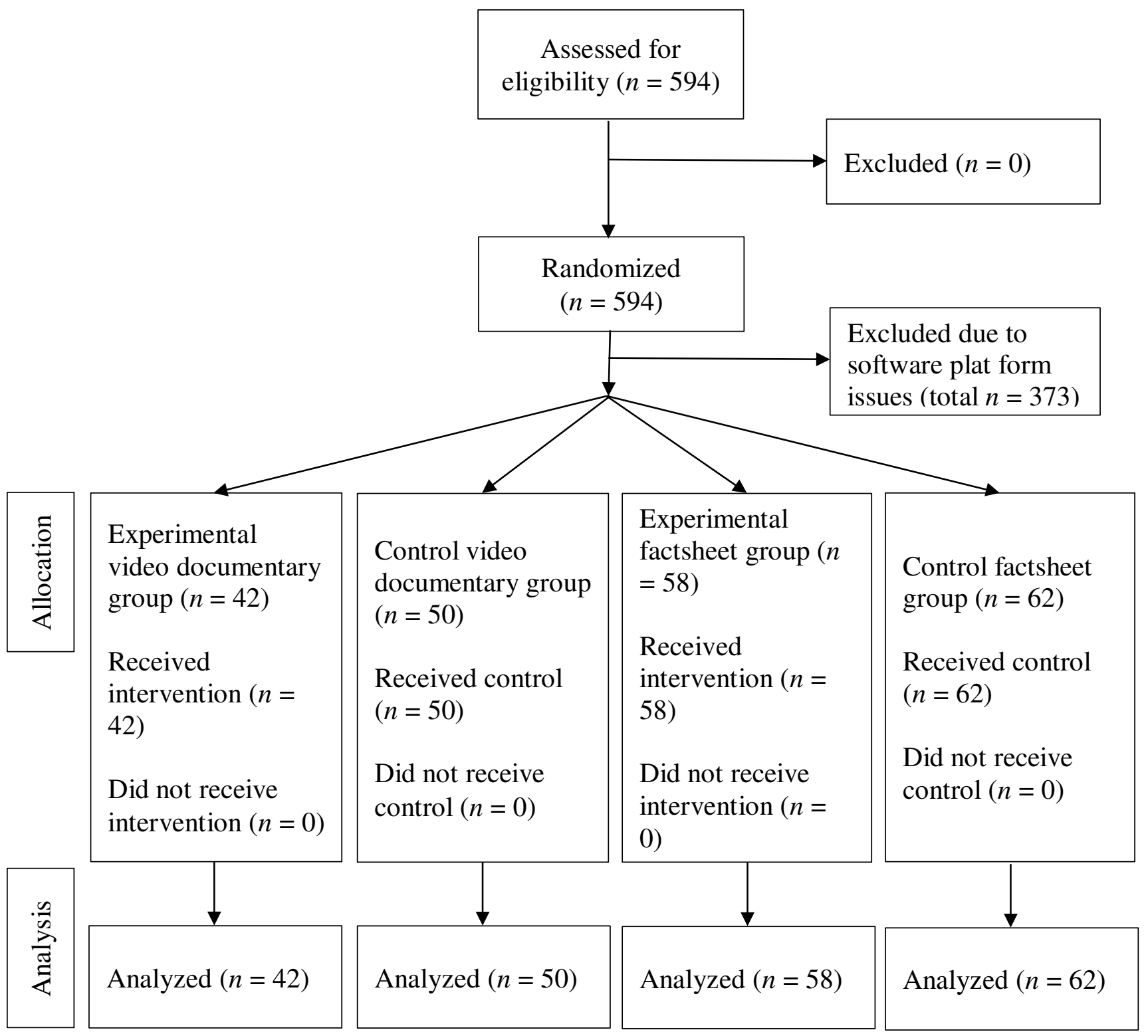

